\title{
MENGHADIRKAN FILM DALAM PEMBELAJARAN \\ BAHASA `JERMAN SEBAGAI BAHASA ASING (DEUTSCH \\ ALS FREMDSPRACHE)
}

\author{
Dwi Imroatu Julaikah \\ Universitas Negeri Surabaya, dwijulaikah@unesa.ac.id
}

\begin{abstract}
German language is taught in Indonesia as a foreign language, or we usually call as DAF (Deutsch als Fremdsprache). This language is taught in formal and non-formal institutions. In this context, it is very important, especially for the teacher to bring interactive and joyfull learning in the classroom, and it is challenging for the teacher. Thus, presenting interesting language in the class, full of innovativation in learning prosess of German language, must be done. One of the choices to get those situations in the classroom is to bring a good media. Film is one alternative that can be presented. This paper discusses how to bring movies in learning a foreign language (German). Further discussion is more about (a) Definition of film, (b) Film, as a medium in teaching learning process, and (c) How to teach German with didactic and methodic in learning German language.
\end{abstract}

Key Words: Film, German, Medien, and foreign language

\section{PENDAHULUAN}

Membawakan pembelajaran yang menarik melalui strategi belajar, metode, media, dan materi yang terkini menjadi tuntutan di dalam kelas bahasa, juga dalam bahasa Jerman. Salah satu media yang layak untuk dihadirkan adalah film. Der Fremdsprachenunterricht braucht die Medien- und Filmbildung, wie jeder andere Schulunterricht (http://www.daf-filmportal.de)

Film sebagai media audio visual menjadi media yang lagi fenomena di kalangan muda maupun dewasa. Sebagai media visual, film memilki nilai tambah tersendiri sebagai alat bantu dalam proses pembelajaran bahasa. Ujung-ujungnya melalui media film, pembelajar berada pada posisi suasana belajar yang menyenangkan. Selain itu, dengan media yang menarik dan beragam, diharapkan dapat menumbuhkan motivasi siswa agar tertarik belajar bahasa Jerman. 
Bagi pembelajaran bahasa Jerman di SMU, kelas yang menarik menjadi sebuah keharusan. Mengapa? di tahun tahun terakhir ini bahasa Jerman, di ajarkan di sekolah (SMU) sebagai peminatan. Kondisi ini menuntut pengajar dan guru agar membawakan kelas bahasa yang menarik menyenangkan dan dapat membawa dampak positif, untuk memotivasi siswa dalam belajar dan memilih bahasa jerman sebagai salah satu peminatan yang patut di pilih. Tentu perkembangan situasi dan kondisi ini memicu dan menjadi tantangan tersendiri bagi guru bahasa Jerman di Indonesia. Dan pembelajaran dengan film menjadi salah satu alternatif yang bisa digunakan.

\section{PEMBAHASAN}

\section{Definisi Film}

Filme sind Texte, film adalah teks (http://www.daf-filmportal.de). Pengertian film menurut UU 8/1992, film merupakan karya cipta seni budaya yang merupakan media komunikasi massa pandang dengar yang dibuat berdasarkan asas sinematografi yang direkam pada pita, video, dan bahan hasil penemuan teknologi dalam segala bentuk, jenis dan ukuran melalui proses kimia dan proses elektronik. Film juga merupakan gambar hidup yang sering disebut movie.(Film ABC Materialien, online)

Film memiliki banyak jenis dan kategori. Untuk proses pembelajaran hampir semua film dapat digunakan, sebagai alat bantu pembelajaran bahasa, sastra dan budaya. Jenis film yang dapat digunakan tersebut, antara lain; (a) Komplettfilme, (b) Trick filme, (3) Adventure Filmed an (4) Video Sequen. Dalam prakteknya, pemilihan terhadap kategori film apa yang digunakan dalam proses belajar dan mengajar tentu disesuakan dengan tujuan pembelajaran, tingkat kesulitan film dan level atau niveau kemampuan bahasa yang telah dimiliki oleh pembelajar, usia dan banyak faktor lainnya.

Film, sebagai Media dalam Pembelajaran 
Dalam pembelajaran, diperlukan media yang menarik dan inovatif sebagai alat bantu. Definisis media itu sendiri merupakan perantara atau pengantar pesan dari pengirim pesan kepada penerimanya. Media dapat pula diartikan wahana pengatur informasi belajar atau penyalur pesan. Dalam pembelajaran, media pengajaran juga diartikan sebagai segala sesuatu yang dapat digunakan untuk menyalurkan pesan, merangsang pikiran perasaan, perhatian dan kemauan siswa sehingga dapat mendorong proses belajar. Bentuk media digunakan untuk meningkatkan pengalaman belajar agar menjadi lebih kongkrit.

Film merupakan salah satu media yang layak untuk dihadirkan dalam pembelajaran bahasa maupun pembelajaran sastra. Ada banyak alasan mengapa film layak untuk di pilih sebagai media dalam pembelajaran bahasa. Pertama; film sebagai salah satu media, film termasuk kategori media pembelajaran yang relativ baru. Hal ini sesuai dengan pendapat Wenschkewitz (2014:1) yang menyatakan bahwa Filme gehoeren zu den relative neuen Medien. Kedua, film memiliki sisi positif lainnya, yaitu disukai oleh berbagai kalangan, baik kalangan muda maupun dewasa. Ketiga, Film juga menjadi media (sosialisasi) penting di era sekarang ini. Menurut Haas (2014:5) Film ist fuer Juegendliche ein in der Freizeit sehr praesentes und beliebtes Medium. Film als Leitmedium d.h es ist das primaere Medium heutiger. Keempat, melalui sebuah film, kita dapat menemukan muatan pesan yang menggambarkan suatu cerita melalui bahasa lisan yang dilakonkan. Mikota (2013:1) menyebutkan bahwa Filme ist eine Geschichte und greifen dabei sowohl auf erzaehlerische Mittel als auf spezielle medienspezifische verfahren zurueck. Selain itu melalui gambar yang bergerak dalam sebuah film, film dapat dapat pula menawarkan berbagai Filmkompetenzen

Dalam pembelajaran bahasa asing, film ini memiliki sisi positif lainnya, seperti yang telah disebutkan diatas. Selain relevant film mampu memberikan gambaran nyata terkailt perbandingan budaya dari bahasa yang sedang dipelajari. Ada banyak jenis film yang dapat digunakan sebagai pilihan media dalam belajar 
bahasa asing. Dalam bahasa jerman. Ada banyak jenis film yang dipakai. Jenis dan kategori film tersebut adalah komedi, action film, petualanagn (adventure). Selain itu (filmeducation, 2013) membedakan jenis genre lain, sebagai berikut; film drama, thriller, komedi, horror, film romantis dan flm documenter, serta filmilmu pengetahuan (science). Sedangkan genre film menurut (Blockwell, 2000) adalah kategori historical, dramatic, narrative, comic, mysterious, sins, personalities.

Untuk pembelajar bahasa Jerman, terutama di tingkat awal, ada film banyak yang bisa digunakan dikelas. Film tersebut misalnya adalah Film animasi pendek (Kursanimationsfilm). Beberapa judul film animasi pendek yang bisa digunakan menurut (Tristan, 1999), misalnya, film dengan judul; (a) Meine Eltern, (b) Gregogrosste Erfindung, (c)Talles, (d) Kleingeld, (d) Dida.

Beberapa film lain yang dapat digunakan dalam pembelajaran bahasa Jerman sebagai bahasa asing (Daf):

(1) Almanya - Willkommen in Deutschland.

Regie: Yasemin Samdereli; DE 2011, FSK: ab 6.

(2) Schwarzfahrer.

Regie: Pepe Danquart; DE 1992, FSK: 0/O.A.

(3) Good Bye, Lenin!

Regie: Wolfgang Becker; DE 2003, FSK: ab 6.

(4) Lola rennt.

Regie: Tom Tykwer; DE 1998, FSK: ab 12.

(5) Sophie Scholl-Die letzten Tage.

Regie: Marc Rothemund; DE 2005, FSK: ab 12.

(6) Kaddisch für einen Freund.

Regie: Leo Khasin; DE 2012, FSK: ab 12.

(7) Jenseits der Stille.

Regie: Caroline Link; DE 1996, FSK: ab 6.

122 | http://journal.unesa.ac.id/index.php/paramasastra 
Dwi Imroatu Julaikah, Menghadirkan Film dalam Pembelajaran...(hlm. 119 - 127)

(8) Die Welle.

Regie: Dennis Gansel; DE 2008. FSK: ab 12.

(9) Ich war neunzehn.

Regie: Konrad Wolf;

DDR 1968, FSK: ab 12.

(10) Meer is nich.

Regie: Hagen Keller; DE 2007, FSK: o.A.

(11) Das Leben der Anderen.

Regie: Florian Henckel von Donnersmarck; DE 2006, FSK: ab 2.

(12) Solo Sunny

Regie: Konrad Wolf; DDR 1980, FSK: ab 12.

Film lainnya yang juga patut untuk dipilih contohnya Erste wege in Deutschland,

Jojo, Deutsche Bahn, Lauf junge lauf, Manolo, dan Alamaya (Goethe Institut).

Film, Didaktik dalam Pembelajaran Bahasa Jerman

Dalam proses pembelajaran dengan menggunakan film, perlu dipertimbangkan banyak hal terkait dengan pemilihan film yang dipakai dalam proses pembelajaran. Dalam http://www.daf-filmportal.de disebutkan bahwa dalam pemilihan media film criteria berikut menjadi persyaratan, yaitu pemilihan tujuan mengapa film itu dihadirkan, pertimbangan referensi dan pertimbangan di daktis methodic yang dipakai dan tema yang akan di pilih.

Sementara itu, dalam praktek di kelas, langkah pembelajaran dalam film bisa dilakukan dengan tiga langkah besar, yaitu Langkah sebelum pemutaran, langkap pembelajaran saat pemutaran film dan setelah selesai dilakukan.

Berikut implementasi secara praktis bagaimana langkah pembelajaran film.

Langkah Sebelum Pemutaran Film

Dalam kegiatan ini siswa dapat dilibatkan dengan pertanyaan seputar film. Tentu saja prognose dan perkiraan awal dari pembelajar terkait film tersebut. 
Pembelajar dapat di stimulus dengan berbagai pertanyaan seputar film tersebut. Misalnya tentang tema film, kira-kira film yang akan ditonton bercerita seputar tema apa?. Pada fase ini beberapa pertanyaan dalam bahasa Jerman yang bisa diajukan, dapat berupa (1) Was heist du bereits ueber den Inhalts?, (2) Warum koente es gehen?, (3) Bildbeschreibung was? wo? wer? Warum?, (4). Der Trailer und Schlagzeilen. In welcher Reihenfolge erscheinen die Schlagzeile?

Langkah Saat Pemutaran Film

Beberapa pertanyaan dapat disisipkan pada saat pemutaran film. Pemutaran film dapat dihentikan sesaat pada sequen-sequen tertentu. Pada saat dihentikan sesaat pembelajar dapat diajukan pertanyaan, seperti isi film, tema inti dan sebagainya (Filminhalt und Zentraler Themen)

Langkah Saat Pemutaran Film Berakhir (Nach dem Film)

Setelah pemutaran selesai total. Pembelajar dapat diberikan pertanyaan, misalnya; apakah pembelajar menyukai film yang telah diputar, di scene yang mana yang paling menarik menurut mereka, gambarkan karakter tokoh utama, tokoh yang disukai atau bahkan tokoh yang tidak disukai. Ungkapkan kesan pembelajar terkait dengan tokoh yang ada dalam film. Pertanyaan tersebut dapat diformulasikan dalam bahasa Jerman sebagai berikut, (a) Wie hat euch der film gefallen, (b) Welche Szenen im Filmwaren besonders gut oder schlecht, (c) Beschreibt den Character der Film Figur, die euch am meisten beeindruckt hat und begruendet ihre Meinung?

Fase lain dalam menghadirkan film di kelas bahasa juga dapat dilakukan dengan langkah pembelajaran dengan fase atau memberikan kalimat tanya W ( $W$ Fragen) kepada peserta didik.

a. Was? (Inhalt, Handlung).

124 | http://journal.unesa.ac.id/index.php/paramasastra 
Peserta didik di stimulus dengan pertanyaan was (apa). Misalnya saja dengan kalimat tanya apa inti dari dari film yang dihadirkan?, Apa kira kira tema film tersebut? Bercerita tentang apa kira kira film tersebut?

b. Wer? (Figuren).

Fase selanjutnya, guru dapat memberikan kalimat tanya siapa? Pertanyaan yang dapat diformulasikan adalah siapa tokoh dalam film tersebut? Siapakah nama pemain actor dan aktris dalam film tersebut?, Siapa sajakah nama- nama pemain dalam film tersebut? Siapakah pemeran utama dalam film tersebut?

C. Wie? (Filmanalyse, Dramaturgie),

Bagaimana jenis film tersebut?, Menurut anda bagaimana kategori jenis film apa? untuk peserta didik yang lebih lanjut bisa juga ditanyakan bagaimana menganalisis film tersebut?

d. Wozu? (Botschaft, Interpretation des Films).

Pertanyaan selanjutnya dapat juga dihadirkan dengan alasan untuk apa film itu dibuat? Siapakah konsumen yang dibidik yang akan menikmati film tersebut? apakah kalangan anak muda, sebuah instansi atau konsumen yang bagaimana?

Khusus Untuk konteks pembelajaran intepretasi film, perlu pula dipahami bahwa dalam sebuah film ada tiga aspek yang harus diperhatikan jika mengintepretasi sebuah film. (vgl. Faulstich 2002: 25f.) dalam http://www.daf-filmportal.de adalah (a) Literarischer Aspekt(Plot, Figuren, Themen, Raum- und Zeitdarstellung, Erzählweise), (b) Dramatischer Aspekt (Rollenbesetzung, Mimik, Gestik, Körpersprache, Maske, Kostüme, Ausstattung des Schauplatzes, Requisiten) dam (c) Cineastischer Aspekt (Bild- und Tongestaltung

Fase lain dalam pembelajaran film ini adalah (a) Block, (b) interval, (c) Sandwich, dan (d) Segment. Berikut penjelasan tentang keempat item tersebut;

(a) Block,

Pengajar menunjukka film secara keseluruhan, mulai dari awal sampai akhir film secara langsung. Atau bisa juga dilakukan dengan cara pembelajar melihat film 
tersebut di rumah, sebelum proses pembelajaran dengna film tersebut dilakukan di kelas. Sehingga peserta didik memiliki bekal awal.

(b) interval,

Film dihadirkan dan di pahami dalam bagian bagian atau sekuen sekuen-dalam kurun waktu yang lebih lama. Pada fase ini film di hadirkan secara terpotong, dan dipahami melalui sekuen sekuen untuk memahami lebih dalam film tersebut.

(c) Sandwich,

Pengajar menghadirkan film pada bagian yang penting, yaitu menunjukkan sekuen yang berisi inti (Inhalts) dari film tersebut,

(d) Segment

Menganalisis film, dan focus pada scene tertentu

\section{PENUTUP}

Film sebagai salah satu produk media dalam pembelajaran, tentulah sangat baik digunakan di kela bahasa, terutama di kelas bahasa jerman sebagai bahasa asing $(D a f)$. Tentu masih banyak produk media lain yang dapat digunakan dalam kelasa bahasa jerman, seperti teks sastra dengan berbagai ragamnya. Perlu rasanya kerja keras, ide dan variasai pengajaran yang dilakukan oleh pengajar agar pembelajaran bahasa, sastra dan budaya di kelas bahasa jerman dapat mencapi tujuan pembelajaran dengan sempurna, utamanya dengan menggunakan film sebagai media. Pemahaman dan kepiawaian guru atau pengajar untuk dapat memilih dan menerapkan media (dalam hal ini film) yang cocok menjadi kunci keberhasilan, sekaligus tantangan dalam pembelajaran bahasa Jerman sebagai bahasa asing di Indonesia.

126 | http://journal.unesa.ac.id/index.php/paramasastra 
Dwi Imroatu Julaikah, Menghadirkan Film dalam Pembelajaran...(hlm. 119 - 127)

\section{DAFTAR RUJUKAN}

Film ABC Materialien No.55. Dystopischer Jugendfilm -trend themen und Motive. Online Filmeducation.org asses onlineJanuari 2017.

Goethe institute Bressel. Arbeitsmaterial zum Film. Online diunduh Agustus 2016.

Hahn, Natalia. 2015. Filmbildung im deutschdidaktischen und im DaFdidaktischen Handlungsfeld: eine kontrastive Perspektive. In: Welke, Tina; Faistauer, Renate (Hrsg.). 2015. Film im DaF/DaZ-Unterricht. Beiträge der XV. IDTBozen. Wien: Praesens-Verlag, 13.

Haas, Sabine. 2014. Film im Deutschunterricht Praktikumarbeit. Wien.9 Schulstufe/Realgymnasium http://www.daf-filmportal.de.

Mikota, Jana. 2013. Film Ab! Verfilmungen Im Deutschunterricht. Methoden Fuer Deutschunterricht Und Lesefoerderung. Online Di Unduh Tanggal 22 Mei 2016 UU No 8/1992 Tentang Film.

Robert Staun, dkk. 2000. Blockwell Publischer.online.

Tristan lay. 1999. Film sehen und lernen. Film spesifische Arbbeit im fremdspracheunterricht .

Wenschewitz, Gerhard, Dr dkk. 2014. Didaktik und Methodikdes Filmeinsatzes im allgemeinen bilder den chemieunterricht des Gymnasium. Online diunduh Agustus 2016.

Wuehrl, Claudia. 2010. Didaktic der Deutschen Sprache und Literatur. Koloqium fuer staatsexamenskandidaten SS 2010. Universitaet Bayruth. 